\title{
Satisfaction of Adult Patients about Their Smile Aesthetics Compared to Dental Professionals Observation
}

\author{
Basil Yousef Alamassi ${ }^{*}$, Mohammad Saleh Al Onazi², Ahmad Abdullah Al Zoman1 \\ ${ }^{1}$ Department of Restorative Dentistry, Riyadh Colleges of Dentistry and Pharmacy, Riyadh, Saudi Arabia \\ ${ }^{2}$ Department of Dentistry, Security Force Hospital, Riyadh, Saudi Arabia \\ Email: ^dr_basil@riyadh.edu.sa,dr-zoman@hotmai.com,msapt_1@hotmail.com
}

How to cite this paper: Alamassi, B.Y., Al Onazi, M.S. and Al Zoman, A.A. (2016) Satisfaction of Adult Patients about Their Smile Aesthetics Compared to Dental Professionals Observation. Open Journal of Stomatology, 6, 236-244.

http://dx.doi.org/10.4236/ojst.2016.611029

Received: October 19, 2016

Accepted: November 21, 2016

Published: November 24, 2016

Copyright $\odot 2016$ by authors and Scientific Research Publishing Inc. This work is licensed under the Creative Commons Attribution International License (CC BY 4.0).

http://creativecommons.org/licenses/by/4.0/

\section{Abstract}

Objective: The aim of the present study was to evaluate personal satisfaction of adult dental patients about their smiles aesthetics in comparison to dental professionals view. Method: One hundred twenty adult patients (76 male and 44 female) visiting the screening clinics of Riyadh colleges of dentistry and Pharmacy were asked to evaluate their smiles by completing a questionnaire containing five questions concerning five aesthetic elements which are: Overall smile; color; shape; alignment of their teeth; and appearance of their gum during smiling. They were asked to rate each of the five categories in Visual Analog Scale (VAS) graded from 0 to 10. A smiling photograph was taken for each patient to be evaluated by two restorative specialists using the same scale. Patients and dental professional mean evaluation scores were statistically analyzed for any significant differences. Result: The average age of the patients was 39.1 years. The mean patients' satisfaction with their own smiles was [6.47] on the VAS which was statistically higher than the average of dentists' evaluation scores [4.95] $(\mathrm{p}<0.05)$. Patients were most satisfied with the gingival show when smiling [6.8] and least satisfied with teeth color [6.01]. The patients gave a statistically higher evaluation scores than the dental professionals in the five categories of the study which indicates higher satisfaction regarding their own smile aesthetics $(\mathrm{p}<0.05)$. Female patients were less satisfied about their smiles [5.98] than the male participants [6.74]. Patients visiting the clinic for aesthetic reasons gave a lower evaluation scores [5.65] than those visiting the clinic for non-aesthetic reasons [6.67]. Conclusion: Patients' satisfaction about their dental aesthetics was statistically higher than the dental professional assessments. Dental professionals appear to be more critical in their evaluation of patients smile aesthetics. Age showed no significant relation with the level of satisfaction while gender and reason of dental visit showed a significant relation with patients smile satisfaction. 


\section{Keywords}

Dental, Aesthetic, Satisfaction, Smile, Perception

\section{Introduction}

One of the main goals of dental treatment is to provide the patient with functional, healthy and esthetic dentition. The field of dental aesthetics is a complicated $t$ with a. branch of dentistry because of the subjective nature of dental aesthetic judgment. We should not forget that perception varies from person to person and this could be influenced by many factors including age, personal experience, education, media, and social environment [1]. Focus on esthetics and dental appearance continues to grow and patients frequently attend dental offices seeking to improve the appearance of their teeth. Currently media play an important role in improving the knowledge of the patients about the ideal smile which may explain the increased demand for aesthetic dental treatment.

In addition to the subjective judgment and in contrast to the laypeople, dental professionals usually rely on aesthetic scientific rules in expressing their opinions about smile aesthetics. It is common understanding that dental appearance has been shown to influence other people judgment of person's facial attractiveness as well as personal characteristics [2]. Smile is formed by flexing the muscles near both ends of the mouth. When that smile is destroyed by dental disease, the result is often loss of self-esteem and damage to overall physical and mental health [3]. The smile is determined by the position, shape, size and shade of the teeth; the position, texture, color and lines of the gingiva and lips; and the shape of the jaws [4].

Several studies have compared smile assessments between dental patients and dentists. The investigators in these studies used photographs, often with software-imaging programs to assess the importance of the shape, symmetry and proportions of maxillary central incisors; the presence and shape of the interdental papilla; the presence of a midline diastema; the gingival to-lip relationship; and the impact of the buccal corridor [4]-[9]. The majority of the studies showed that dentists are far more critical in their esthetic perceptions than are patients in general [2] [4] [6] [7]. Gannke and Fardal (2007) found in their study that dentists' are more critical in evaluating smile aesthetics compared to patients self-evaluation. Dentists should be aware that patients who seek esthetic services may have different perceptions of their smiles than patients who do not express such desires [2].

Teeth color is a highly significant factor in perception of smile attractiveness. It is known that laypeople prefer smiles with lighter teeth shade [4] [5] [10]. Naveh et al. in 2007 conducted a study on 407 subjects to compare patients satisfaction of their aesthetics with the dental professional evaluation. They found $37.3 \%$ were dissatisfied with their dental appearance and tooth color was the primary reason for dissatisfaction followed by poor tooth alignment (23.7\%). Patients' opinions of their own smiles were 
significantly higher than the clinicians' assessments of their smiles [4].

Tooth color usually is the category which shows the majority of the patients' dissatisfaction [10] [11] [12]. Tin et al. in 2011 found in their study on 235 patients that $56.2 \%$ were not happy with the color of their teeth and dissatisfaction with tooth color was significantly higher in female than male patients [10]. Age, sex, and level of education are known to influence a person's satisfaction with his or her oral appearance [2] [13] [14]. In contrast to the majority of studies, Krishnan et al. in 2008 found no perception difference between the specialists and the laypersons on overall smile evaluation [15].

Limited information is available about patients' perception toward their ideal smile in the Kingdom Saudi Arabia (KSA). Furthermore, very few studies have been published regarding the difference between how patients view their own smiles and how dentists assess these smiles based on a scientific background. The aim of this study was to evaluate personal satisfaction of the adult patients visiting dental clinics of Riyadh Colleges of Dentistry and Pharmacy (RCsDP) about their dental and smile aesthetics and to compare their assessment with dental professionals' evaluation.

\section{Material and Method}

\subsection{Study Population}

The subjects in this study were adult patients visiting the screening clinic of RCsDP, Riyadh, KSA in the period from $6^{\text {th }}$ march to $17^{\text {th }}$ march 2016 . One hundred twenty adult patients were included in the study.

\subsection{Inclusion Criteria}

- Adult patients.

- Not under orthodontic treatment and with no dental veneers.

- No missing teeth in the anterior teeth.

\subsection{Data Collection Tool}

A smile self-evaluation questionnaire specially designed for this study containing-in addition to personal data-five questions about five elements of dental aesthetic used in the study. The participants were asked to mark on a $10 \mathrm{~cm}$ horizontal line how satisfied they are with their overall smile; shape; teeth; color; alignment of their teeth; and appearance of gum during smiling. For each of the five components of the questionnaire, they were asked to rate their satisfaction in Visual Analog Scale (VAS) graded from 0 to 10 where 10indicated most satisfied and zero the least. The VAS method has been used in other investigations and is a tool of proven scientific validity.

The participants were asked to evaluate their smile aesthetics from memory, without viewing their smile in the mirror during this study. The subjects completed the survey on site in the screening clinic.

A standardized smiling frontal photograph was taken at the completion of the survey to be evaluated by two dental restorative specialists from department of restorative den- 

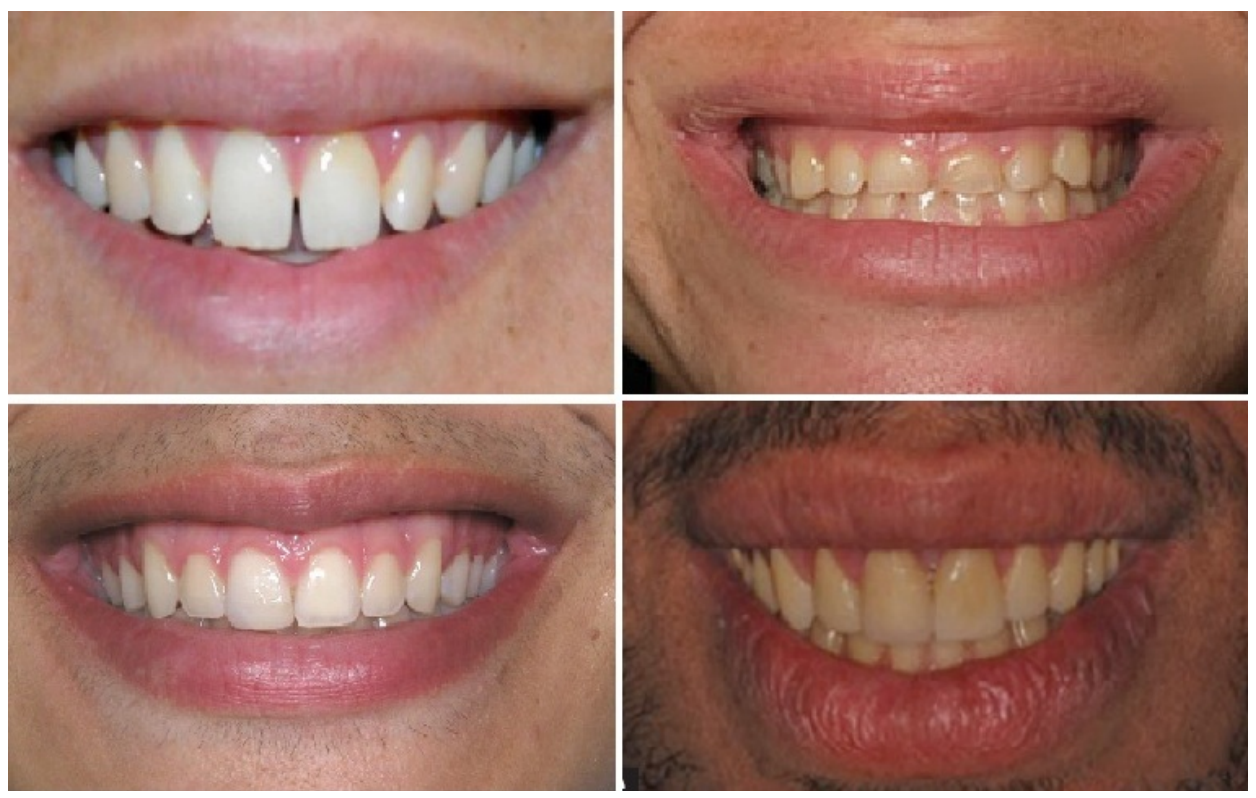

Image 1. Sample of smiling photographs for the participants in the study.

tistry using the same scale (Image 1).

No names or identifiers were written on the questionnaire. A completed questionnaire indicated the consent to participate in the study. Anonymity and confidentiality were assured.

\subsection{Statistical Analysis}

Descriptive analysis was undertaken to present an overview of the findings of the characteristic of the population and their perception toward their own smile aesthetics. The Statistical Package for Social Sciences Software release 20.0 (SPSS Inc., Chicago, IL, USA) was used for data analysis. Parametric test was used to compare the mean values of patients and dentist scores with the assumption of normal distribution $(p>0.05)$. Independent sample t-test was used to examine differences in mean scores of patients satisfaction and dentists evaluations. The confidence level was set at $\mathrm{p} \leq 0.05$.

\subsection{Ethical Approval}

This study was approved by the ethics committee in RCsDP. The participants were given a description about the study and how their photographs would be used and subsequently given consent forms to allow use of their photographs in this study.

\section{Results}

One hundred twenty adult patients (76 male and 44 female) with mean age of 39.1 years participated in the study. The mean $( \pm \mathrm{SD})$ patients' satisfaction scores about their own smiles was $(6.47 \pm 1.54)$ on VAS which was significantly higher than the dental professionals evaluation scores $(4.95 \pm 1.33)(\mathrm{p}=0.00)$. Patients were most satisfied with their gum while smiling with a score of $6.80(2.06 \pm)$ and least satisfied with tooth color with 
a score of $6.01( \pm 1.96)$. Restorative dental specialists gave the highest evaluation for gum show during smiling $(5.95 \pm 2.10)$ and lowest score was for smile overall (4.45 \pm 1.67). When comparing the level of patients' satisfaction about their smiles to doctors view in the five categories of the study separately, results revealed that patients gave significantly higher evaluation scores in the five categories of the study as presented in Table 1 and Figure 1. Female patients showed lower evaluation scores for their smiles $(5.98 \pm 1.53)$ than male patients $(6.74 \pm 1.48)$ which indicates less satisfaction than male participants. When comparing the mean evaluation scores of participants by gender in to dental professional scores, both male and female groups showed significantly lower evaluation scores on VAS than dental professional in the five category of the study (Figure 2). Statistical analysis revealed a significant deference between male and female groups with $\mathrm{p}$ value $=0.009$ (Table 2 ). The group of patients who visited the dental clinic for aesthetic reasons $(n=24)$ recorded lower mean scores in evaluating their smile $(5.65 \pm 165)$ than the group of patients visiting the clinic for non-aesthetic reasons $(\mathrm{n}=96)$ with a score $(6.67 \pm 1.45)$ and the difference was statistically significant ( $\mathrm{p}$ $=0.003$ ) (Table 3$)$. Age groups showed statistically no influence on patients' judgment

Table 1. The mean $( \pm \mathrm{SD})$ patients' and dentists' smile evaluation scores in the five categories of the study.

\begin{tabular}{cccc}
\hline Category & Mean Patients Evaluation & Mean Dentists Evaluations & Sig. (P value) \\
\hline Smile overall & $6.66 \pm 1.75$ & $4.45 \pm 1.67$ & 0.000 \\
Shape & $6.55 \pm 1.94$ & $4.62 \pm 1.69$ & 0.000 \\
Color & $6.01 \pm 1.96$ & $5.09 \pm 1.58$ & 0.004 \\
Alignment & $6.31 \pm 2.16$ & $4.65 \pm 1.86$ & 0.000 \\
Gum & $6.80 \pm 2.06$ & $5.95 \pm 2.10$ & 0.000 \\
Average & $6.47 \pm 1.54$ & $4.95 \pm 1.33$ & 0.000 \\
\hline
\end{tabular}

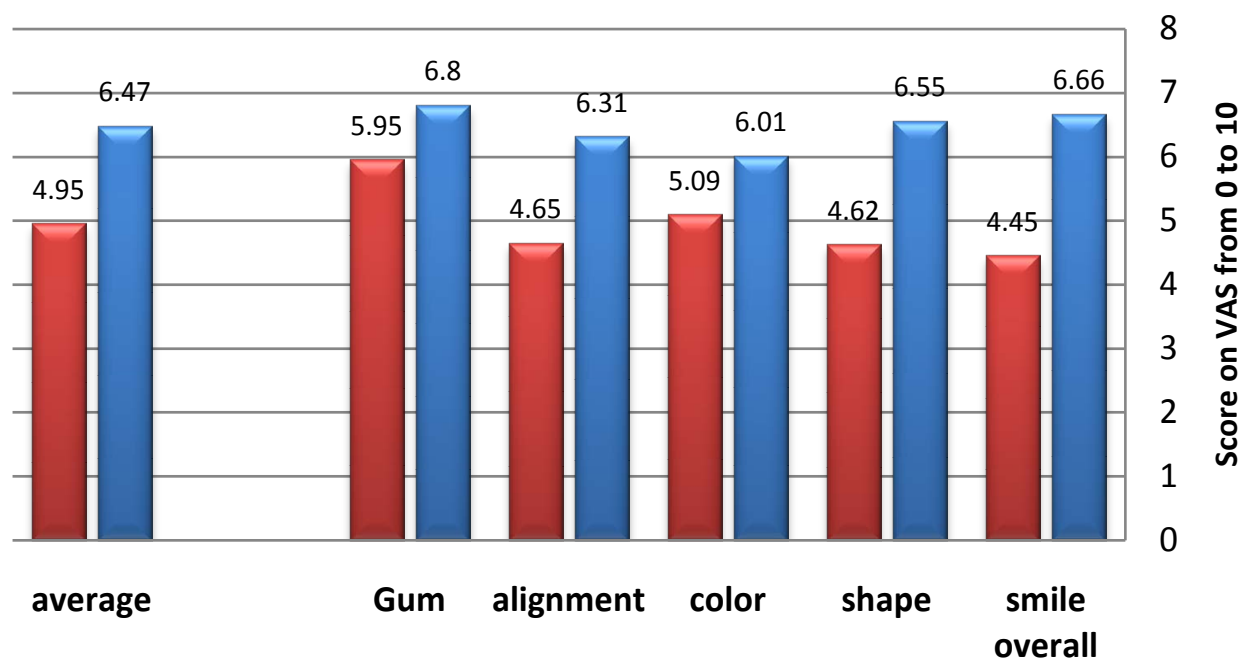

$\square$ Patient Evaluation scores $\quad$ Doctors Evaluation scores

Figure 1. Mean patients and dentists scores in the five categories of the study $(\mathrm{P}<0.05)$. 


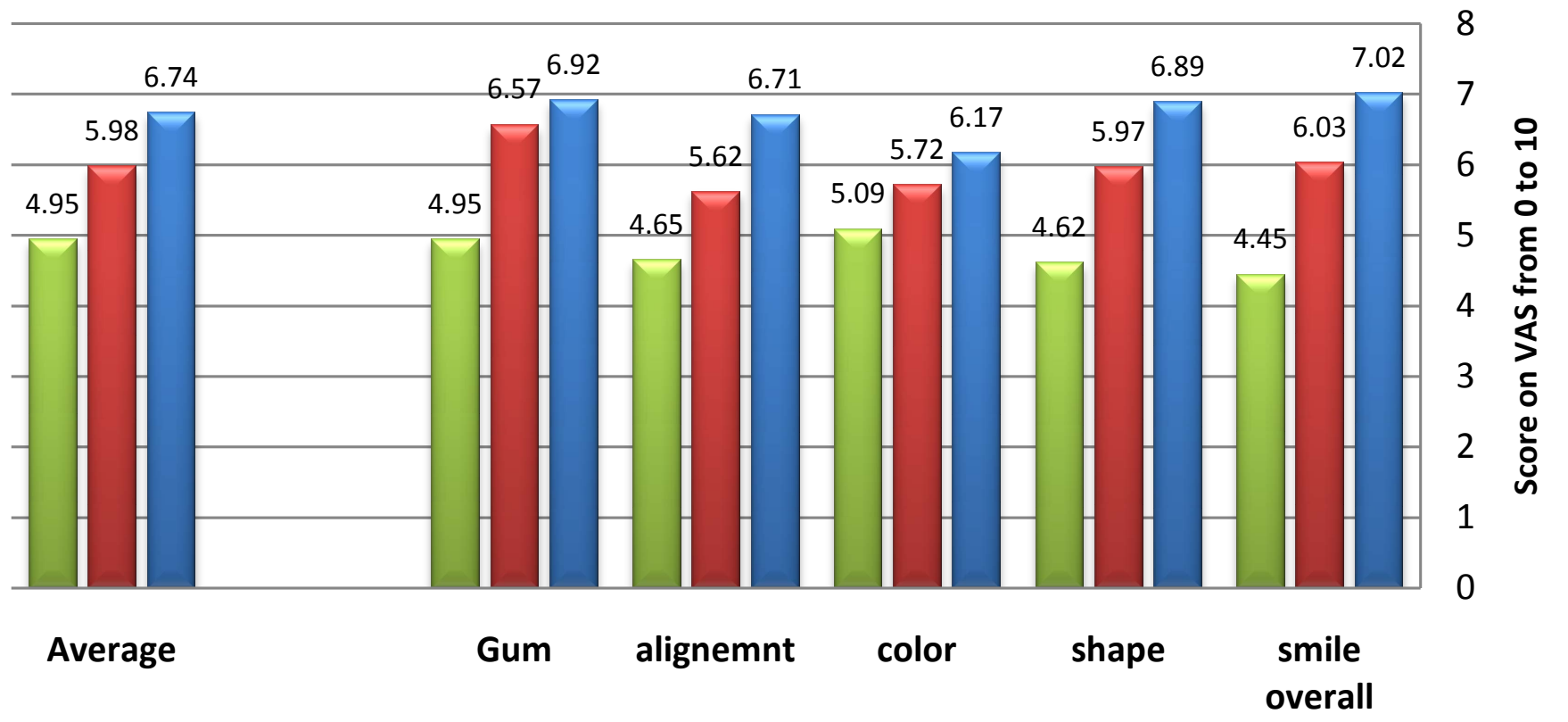

\section{Male $\square$ Female $\square$ Dentists}

Figure 2. Mean smile aesthetic evaluation scores by gender in comparison to dental professional evaluation in the five categories of the study $(\mathrm{P}<0.05)$.

Table 2. Mean $( \pm S D)$ smile evaluation scores by gender.

\begin{tabular}{|c|c|c|c|c|}
\hline Gender & Number (\%) & Mean Evaluation scores & $\mathrm{SD}$ & Sig. (P Value) \\
\hline Male $(n=76)$ & $76(63.3 \%)$ & 6.74 & 1.48 & \multirow[b]{2}{*}{0.009} \\
\hline Female $(\mathrm{n}=44)$ & $44(36.7 \%)$ & 5.98 & 1.53 & \\
\hline
\end{tabular}

Table 3. Mean $( \pm S D)$ smile evaluation scores for the patients according to the reason of dental visit (aesthetic and non-aesthetic).

\begin{tabular}{|c|c|c|c|c|}
\hline Reason for current dental visit & Number of patients (\%) & Smile evaluation mean & $\mathrm{SD}$ & Sig. (P Value) \\
\hline Aesthetic & $24(20 \%)$ & 5.65 & 1.65 & \multirow{2}{*}{0.003} \\
\hline Non-aesthetic & $96(80 \%)$ & 6.67 & 1.45 & \\
\hline
\end{tabular}

and satisfaction about their smiles (Table 4).

\section{Discussion}

The current study was designed to assess patients' satisfaction about their smiles and compare their evaluation with dental professional assessments of the patient smile recorded on photographs. Visual Analog Scale (VAS) was utilized as the method of evaluation of the smiles for both patients' and dental professionals. The VAS is a valid and reliable method that can be applied to evaluate patients' and dentists' perceptions about dental aesthetics.VAS has been widely used in the assessment of dental aesthetics for public and it found to be suitable for the purpose of discriminating the levels of self as- 
Table 4. Mean $( \pm \mathrm{SD})$ smile evaluation scores of patients by age group.

\begin{tabular}{ccccc}
\hline Age Group(Yrs.) & Number (\%) & Mean Evaluation & SD & 1.67 \\
\hline $18-30$ & $34(28.3 \%)$ & 6.50 & 1.56 & 0.385 \\
$31-41$ & $47(39.2 \%)$ & 6.24 & 1.38 \\
\hline 41 & $39(32.5 \%)$ & 6.71 & Palue $)$ \\
\hline
\end{tabular}

sessment of dental aesthetics, as employed in the present study. VAS as a measurement tool is characterized by being simple to administer.

It must be emphasized that dentists and the patients did not evaluate the smiles in the same way. The esthetic perception of a smile is very personal and varies according to the sensibility of each subject. Patients' subjective evaluation to their smiles could be influenced by media, cultural background, level of education and socioeconomic status while dentists rely on aesthetic principals for the ideal smile. The patients were asked to evaluate their smiles from their memories and not using photographs or mirrors.

Results of the current study showed that dental professionals appear to be more critical in evaluating patients smile aesthetics than the patients themselves. This could be attributed that their scientific background about principals of smile aesthetics make them capable of picking out small dental defects that is not noticeable by the patients. Another reason that may explain that difference is that dental professionals looks to the general oral health of the patients through these photographs such as observing presence of plaque, calculus, inflamed gingival, which are not perceived by most of the patients. In our study, a statistically significant difference existed between patients' satisfaction about their smiles and dental professionals view in the five categories of the study (smile overall, shape, color, gum show during smiling, alignment). The finding that the dentists gave lower evaluation cores for smile aesthetics than the patients is similar with the reports of most studies did this comparison [4]-[9]. Our finding reveals that dental professional are more sensitive to any defect in smile esthetics than the patient themselves, a finding that is not in agreement with that of the study done by Krishnan et al. (2008) [15]. The participants gave the least scores for their teeth colors which indicate the least satisfaction of the five categories of the study. Similar finding was found in the most of the studies which compared the perception of the patients or laypeople to dental professionals' view [10] [11] [12].

The mean doctors' evaluation scores on VAS was below 5 which clearly reflects generalized dissatisfaction with the patients' smile aesthetics.

The gum show during smile is one of the most important aspects of smile aesthetics. The acceptable gum show during smiling can vary widely between different persons and dental professionals. Kokish and Colleagues investigated the gingival display and reported that $3 \mathrm{~mm}$ of $\mathrm{g}$. display represent the threshold of acceptability. The mean participants satisfaction scores about gum was the highest among the five categories included in the smile evaluation in the present study. This could indicate a relative satisfaction of the patients about their gum show during smiling and this could be attri- 
buted to that patients may not giving the gum a lot of concern in evaluating their smiles .

Female patients appears to be more critical than male patients and they gave lower evaluation rates than male which is similar to the findings of Tin (2011) [10] and Neumann et al. (1989) [13]. This might be due to higher expectations of dental attractiveness for female than male. Our study population included any adult patients visiting the dental clinic and the majority of them were not for aesthetic reasons. The group visiting the clinic for aesthetic reason showed statistically significant lower score of evaluation for their smiles than others. This could be attributed that those asking aesthetic treatment usually are more aware about their dental aesthetic problems.

In our study, Patients appears to be not sufficiently aware about smile aesthetics and further educational efforts should be carried out in order to improve their awareness about ideal smile. Other factors may affect patients' perception toward their smiles recommended to be investigated. Such factors include level of education, self confidence and its relation to smile aesthetics, occupational factors and psychological influence of smile aesthetics on the person.

It could be proposed that patients in higher educational level may able to perceive their smile defects better than lower levels. One limitation in this study was the lack of correlation between the socioeconomic status, level of education, cultural background and smile perception. Future researches is needed to explore the impact of these factors on patients' perception of smile aesthetics. Furthermore, It is not clear from this study at what level of satisfaction or dissatisfaction the patients might seek dental aesthetic care.

\section{Conclusion}

It appears from the present study that dental professionals appear to be more critical in their evaluation of patients smile aesthetics. Dental professionals gave lower smiles evaluation scores than the patients themselves in the five elements of the study. Female patients' and patients visiting the clinic for aesthetic reason found to have significantly less satisfaction about their own smiles if compared to male and patients visiting the clinic for non-aesthetic reason respectively. Age didn't show any statistically significant relation with dental aesthetic satisfaction. Highest mean score-level of satisfaction-of the patients was in the category of gingival and the least was in the teeth color. While the highest mean evaluation scores of the dental professionals was for gum show during smiling and least mean scores was for smile overall category.

\section{Conflict of Interest}

There is no conflict of interest.

\section{References}

[1] Rosenstiel, S.F. (2000) Dentists' Preferences of Anterior Tooth Proportion-A Web Based Study. Journal of Prosthodontics, 9, 123-136. https:/doi.org/10.1053/jopr.2000.19987 
[2] Jornung, J. and Fardal, O. (2007) Perceptions of Patients' Smiles. Comparison of Patients' and Dentists' Opinions. JADA, 138, 1544-1553.

https:/doi.org/10.14219/jada.archive.2007.0103

[3] Ingber, F.K. (2006) You Are Never Fully Dressed without a Smile. Journal of Esthetic and Restorative Dentistry, 18, 59-60. https:/doi.org/10.2310/6130.2006.00011.x

[4] Samorodnitzky-Naveh, G.R., Geiger, S.B. and Levin, L. (2007) Patients' Satisfaction with Dental Esthetics. The Journal of the American Dental Association, 138, 805-808. https:/doi.org/10.14219/jada.archive.2007.0269

[5] Sabherwal, R.S., Gonzalez, J. and Naini, F.B. (2009) Assessing the Influence of Skin Color and Tooth Shade Value on Perceived Smile Attractiveness. The Journal of the American Dental Association, 140, 696-705. https:/doi.org/10.14219/jada.archive.2009.0256

[6] Kokich, V. and Kiyak, H. (2006) Perceptions of Dental Professionals and Laypersons to Altered Dental Esthetics: Asymmetric and Symmetric Situations. American Journal of Orthodontics and Dentofacial Orthopedics, 130, 141-151.

https:/doi.org/10.1016/j.ajodo.2006.04.017

[7] Kokich Jr., V.O., Kiyak, H.A. and Shapiro, P.A. (1999) Comparing the Perceptions of Dentists and Lay People to Altered Dental Esthetics. Journal of Esthetic and Restorative Dentistry, 11, 311-324. https:/doi.org/10.1111/j.1708-8240.1999.tb00414.x

[8] Yu, Y.C.P., Alamri, A., Francisco, H., Cho, S.-C. and Hirsch, S. (2015) Interdental Papilla Length and the Perception of Aesthetics in Asymmetric Situations. International Journal of Dentistry, 2015, 125-146. http://dx.doi.org/10.1155/2015/125146

[9] Gracco, A., Cozzani, M., D’Elia, L., Manfrini, M., Peverada, C. and Siciliani, G. (2006) The smile Buccal Corridors: Aesthetic Values for Dentists and Laypersons. Progress in Orthodontics, 7, 56-65.

[10] Tin, O.M., Saddki, N. and Hassan, N. (2011) Factors Influencing Patient Satisfaction with Dental Appearance and Treatments They Desire to Improve Aesthetics. BMC Oral Heath, 23, 11-16.

[11] Akarslan, Z.Z., Sadik, B., Erten, H. and Karabulut, E. (2009) Dental Esthetic Satisfaction, Received and Desired Dental Treatments for Improvement of Esthetics. Indian Journal of Dental Research, 20, 195-200. https:/doi.org/10.4103/0970-9290.52902

[12] Dunn, W.G., Murchison, D.F. and Broom, J.C. (1996) Esthetics: Patients' Perceptions of Dental Attractiveness. Journal of Prosthodontics, 5, 166-171. https:/doi.org/10.1111/j.1532-849X.1996.tb00292.x

[13] Neumann, L.M., Christensen, C. and Cavanaugh, C. (1989) Dental Esthetic Satisfaction in Adults. $J A D A, 118,565-570$. https:/doi.org/10.14219/jada.archive.1989.0077

[14] Vallittu, P.K., Vallittu, A.S. and Lassila, V.P. (1996) Dental Aesthetics: A Survey of Attitudes in Different Groups of Patients. The Journal of Dentistry, 24, 335-338. https:/doi.org/10.1016/0300-5712(95)00079-8

[15] Krishnan, V., Daniel, S., Lazar, D. and Asok, A. (2008) Characterization of Posed Smile by Using Visual Analog Scale, Smile Arc, Buccal Corridor Measures, and Modified Smile Index. American Journal of Orthodontics and Dentofacial Orthopedics, 133, 515-523. https:/doi.org/10.1016/j.ajodo.2006.04.046 
Submit or recommend next manuscript to SCIRP and we will provide best service for you:

Accepting pre-submission inquiries through Email, Facebook, LinkedIn, Twitter, etc. A wide selection of journals (inclusive of 9 subjects, more than 200 journals)

Providing 24-hour high-quality service

User-friendly online submission system

Fair and swift peer-review system

Efficient typesetting and proofreading procedure

Display of the result of downloads and visits, as well as the number of cited articles

Maximum dissemination of your research work

Submit your manuscript at: http://papersubmission.scirp.org/

Or contact ojst@scirp.org 